\title{
A mechanism for the proapoptotic activity of ursodeoxycholic acid: effects on Bcl-2 conformation
}

\author{
M Castelli ${ }^{1}$, JJ Reiners $\mathrm{Jr}^{2}$ and D Kessel ${ }^{\star, 3,4}$ \\ 1 Cancer Biology Program, Wayne State University School of Medicine, Detroit, \\ MI 48201, USA \\ 2 Institute of Environmental Health Sciences, Wayne State University, Detroit, MI \\ 48201, USA \\ 3 Department of Pharmacology, Wayne State University School of Medicine, \\ Detroit, MI 48201, USA \\ 4 Department of Medicine, Wayne State University School of Medicine, Detroit, \\ MI 48201, USA \\ * Corresponding author: D Kessel, Department of Pharmacology, Wayne State \\ University School of Medicine, 540 E. Canfield Street, Detroit, MI 48201, USA. \\ Tel: 313577 1766; Fax: 313577 6739; E-mail: dhkessel@med.wayne.edu
}

Received 22.7.03; revised 21.1.04; accepted 06.2.04

Edited by $G$ Nunez

\begin{abstract}
Ursodeoxycholic acid (UDCA), a relatively nontoxic bile acid, enhanced the apoptotic response of tumor cells to both photosensitizers that cause photodamage to Bcl-2 and to the nonpeptidic $B C l-2 / B C l-x_{L}$ antagonist $H A 14-1$. The latter agent binds to the surface pocket formed by the $\mathrm{BH} 1, \mathrm{BH} 2$ and $\mathrm{BH} 3$ domains of $\mathrm{Bcl}-2$ and $\mathrm{Bcl}-\mathrm{x}_{\mathrm{L}}$. Fluorescence polarization studies indicated that affinity of $\mathrm{HA14-1}$ for $\mathrm{Bcl}-2$ was enhanced in the presence of UDCA. Moreover, Bcl-2 photodamage was promoted by UDCA using a photosensitizing agent with affinity for the endoplasmic reticulum, a site of $\mathrm{Bcl}-$ 2 localization. Fluorescence resonance energy transfer (FRET) studies revealed that the proximity of $\mathrm{Bcl}-2$ to a hydrophobic photosensitizing agent embedded in liposomes was enhanced by UDCA. Since photodamage will occur only if a protein is in close contact with a photosensitizing agent, we propose that these findings support the hypothesis that UDCA causes a conformational change in Bcl-2, promoting HA14-1 binding and enhancing affinity for certain membrane-bound photosensitizers.

Cell Death and Differentiation (2004) 11, 906-914.

doi:10.1038/sj.cdd.4401433
\end{abstract}

Keywords: apoptosis; Bcl-2; CPO; NPe6; SnET2; photodynamic therapy (PDT)

Abbreviations: CPO, 9-capronyloxy-tetrakis(methoxyethyl) porphycene; DCA, deoxycholic acid; DEVD-R110, asp-glu-valasp-rhodamine 110 (fluorogenic caspase-3 substrate); ER, endoplasmic reticulum; flu-Bak, 5-carboxyfluorecein coupled to the $N$ terminus of a peptide GQVGRQLAIIGDDINR derived from the BH3 domain of Bak; HA14-1, ethyl 2-amino-6-bromo-4-(1cyano-2-ethoxy-2-oxoethyl)-4H-chromene-3-carboxylate; HO342, Höchst dye HO33342; mTHPC, meta-(tetrahydroxyphenyl) chlorin; $\mathrm{NPe6}, \mathrm{N}$-aspartyl chlorin e6; $P$, fluorescence polarization value; PDT, photodynamic therapy; SnET2, tin etiopurpurin; UDCA, ursodeoxycholic acid.

\section{Introduction}

Photodynamic therapy (PDT) is a procedure for cancer control using drugs that sensitize neoplastic tissues and their vasculature to light. ${ }^{1}$ The basis of this therapy is the ability of the photosensitizing agents to catalyze the light-mediated conversion of dissolved oxygen to a highly toxic product, singlet molecular oxygen. The latter can catalyze oxidative damage to proteins and lipids that are in very close proximity to the sensitizer. ${ }^{1}$ The subcellular targets for photodamage vary among the different photosensitizing agents. In 1999, we identified the target of an important class of photosensitizing agents: the antiapoptotic protein $\mathrm{Bcl}-2 .^{2}$ Agents in this class include the tin etiopurpurin SnET2, the phthalocyanine Pc 4, the chlorin $m$-THPC and a porphycene termed 9-capronyloxytetrakis(methoxyethyl) porphycene (CPO). ${ }^{2-6}$ It is likely that any photosensitizing agent that localizes in the vicinity of $\mathrm{Bcl}-2$ will be in this drug class. We and Oleinick's group have examined the consequences of $\mathrm{Bcl}-2$ photodamage and subsequent inactivation. These include release of cytochrome $c$ from mitochondria, activation of caspase-3 and initiation of the apoptotic program. ${ }^{4-7}$

Ursodeoxycholic acid (UDCA) (Figure 1) is a nontoxic bile acid that has been reported to protect hepatocytes, hepatoma cells, osteogenic sarcomas and HeLa cells from apoptosis induced by okadaic acid, hydrogen peroxide, ethanol, and more hydrophobic bile acids, for example, DCA. ${ }^{8-15}$ Other investigators found that UDCA promoted apoptosis in some systems. ${ }^{16,17}$ These diverse reports prompted an examination of the effects of UDCA on PDT-induced apoptosis in cell culture. We found a significant promotion of the apoptotic cell death initiated by the photosensitizer SnET2. ${ }^{6,18}$ The latter agent shows affinity for both lysosomes and subcellular membranes including the endoplasmic reticulum (ER), and can therefore mediate photodamage at a variety of sites. ${ }^{3}$ To better delineate the mechanism of action of UDCA, we focused on two sensitizers known to selectively localize in either subcellular membranes including the ER (CPO) or in lysosomes (NPe6). A mode of action of UDCA was suggested by our finding that UDCA also enhanced the proapoptotic effects of the nonpeptidic Bcl-2 antagonist HA14-1. ${ }^{5}$ The latter agent binds to the surface cleft on $\mathrm{Bcl}-2$ and $\mathrm{BCl}-\mathrm{x}_{\mathrm{L}}{ }^{19,20}$ Preliminary results suggested that the proapoptotic effects of UDCA might involve interactions with antiapoptotic members of the Bcl-2 family, a hypothesis that we have pursued in the present work.

\section{Results}

\section{Intracellular accumulation and toxicity of bile acids}

To characterize bile acid transport, we initially examined lysylfluorescein derivatives of UDCA and DCA,${ }^{21}$ but found that these fluorescent analogs were excluded from L1210 cells. 
We therefore prepared radioactive UDCA and DCA to assess bile acid transport, stability of intracellular pools, and competition between these two compounds for cellular binding sites.

A steady state was rapidly reached with ${ }^{14} \mathrm{COOH}$-labeled DCA or UDCA (Table 1), with the equilibrium distribution ratio higher when the more hydrophobic DCA was tested. There was no significant inhibition of ${ }^{14} \mathrm{C}$-DCA or -UDCA accumulation by an equimolar level of either nonradioactive bile acid, indicating a high capacity for accumulation. Once a steady state was reached, washing cells for $10 \mathrm{~min}$ at $37^{\circ} \mathrm{C}$ in fresh medium resulted in a loss of $\sim 90 \%$ of intracellular UDCA or DCA. This was unaffected by prolonging the washing interval to $30 \mathrm{~min}$ or by the presence of unlabeled bile acids in the medium (not shown).

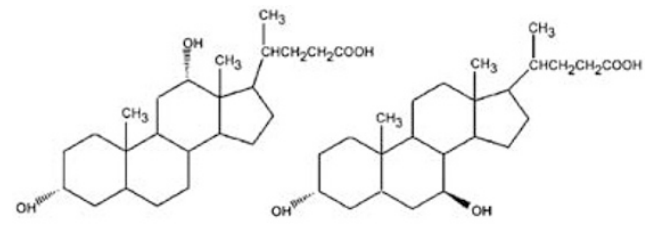

deoxycholic acid ursodeoxycholic acid

Figure 1 Structures of DCA and UDCA. Labeled compounds contain ${ }^{14} \mathrm{C}$ in the terminal $\mathrm{COOH}$ residue

Table 1 Distribution ratio of UDCA and DCA in L1210 cells

\begin{tabular}{lcccc}
\hline & & & \multicolumn{2}{c}{ Distribution ratio } \\
\cline { 4 - 5 } $\begin{array}{l}\text { Additions } \\
\text { (nonradioactive) }\end{array}$ & $\begin{array}{c}\text { Incubation } \\
\text { time }(\mathbf{m i n})\end{array}$ & $\begin{array}{l}\text { Wash } \\
\text { (min) }\end{array}$ & UDCA & DCA \\
\hline None & 1 & No & $1.41 \pm 0.11$ & $3.1 \pm 0.31$ \\
& 3 & & $1.36 \pm 0.18$ & $3.5 \pm 0.35$ \\
& 10 & & $1.38 \pm 0.16$ & $3.1 \pm 0.22$ \\
& 30 & & $1.42 \pm 0.21$ & $3.7 \pm 0.34$ \\
$100 \mu \mathrm{M}$ DCA & 30 & 10 & $0.19 \pm 0.02$ & $0.28 \pm 0.31$ \\
$100 \mu \mathrm{M}$ UDCA & 30 & No & $1.10 \pm 0.21$ & $3.1 \pm 0.25$ \\
& 30 & & $1.38 \pm 0.14$ & $3.0 \pm 0.29$ \\
\hline
\end{tabular}

Cells were incubated with $100 \mu \mathrm{M}{ }^{14} \mathrm{C}$-DCA or ${ }^{14} \mathrm{C}$-UDCA for $1-30 \mathrm{~min}$ at $37^{\circ} \mathrm{C}$, and then either washed with cold isotonic $\mathrm{NaCl}$ or resuspended in fresh medium for $10 \mathrm{~min}$ at $37^{\circ} \mathrm{C}$. In some cases, nonradioactive bile acids were present during the loading incubation. The drug distribution ratio was calculated as [intracellular]/[extracellular] radioactivity. Data represent mean \pm S.D. for three determinations
A 'dose-response' study was carried out over a range of UDCA concentrations from 3-100 $\mu \mathrm{M}$. This experiment revealed that neither the distribution ratio nor the percentage of UDCA retained after washing was altered over this concentration range (Table 2).

Exposure of $\mathrm{L} 1210$ cells to $100 \mu \mathrm{M}$ DCA for 60 min resulted in a substantial loss of viability. This was not reversed by addition of $100 \mu \mathrm{M}$ UDCA, nor was viability significantly affected by $100 \mu \mathrm{M}$ UDCA alone (Table 3).

\section{Photosensitizer localization and PDT effects}

Fluorescence microscopy demonstrated that CPO showed an affinity for a variety of subcellular membranes. NPe6 was localized in lysosomes, and SnET2 was detected at both loci (Figure 2, top). Irradiation of cells sensitized with CPO or SnET2, using LD $_{90}$ PDT conditions, resulted in a substantial loss of $\mathrm{Bcl}-2$, but not of $\mathrm{Bcl}-\mathrm{x}_{\mathrm{L}}$ or Bax, as detected by Western blots (Figure 2, bottom). NPe6 was inactive in this regard. In the presence of $100 \mu \mathrm{M}$ UDCA, the phototoxicities of SnET2 and CPO were substantially promoted, while NPe6 phototoxicity was unaffected (Table 4). Studies shown in Table 4 were carried out with $\mathrm{LD}_{50}$ PDT conditions so that the effect of UDCA could more readily be detected. These results demonstrate that PDT efficacy is promoted by the bile acid UDCA when Bcl-2 is a direct target for photodamage.

As the PDT light dose was increased (using CPO as the sensitizer) a progressively greater loss of $\mathrm{Bcl}-2$ was observed (Figure 3). Bcl-2 photodamage, at each light dose tested, was promoted by an extracellular UDCA concentration of $100 \mu \mathrm{M}$. When cells were incubated with $2 \mu \mathrm{M} \mathrm{CPO}$, irradiated $\left(180 \mathrm{~mJ} / \mathrm{cm}^{2}\right)$ and incubated for an additional $60 \mathrm{~min}$ at $37^{\circ} \mathrm{C}, 32 \pm 5 \%$ of the cell population exhibited an apoptotic

Table 3 Toxicity of UDCA and/or DCA

\begin{tabular}{ccc}
\hline UDCA level $(\mu \mathrm{M})$ & DCA level $(\mu \mathrm{M})$ & Viability $\%(\mu \mathrm{M})$ \\
\hline 0 & 0 & $97 \pm 2$ \\
100 & 0 & $92 \pm 3$ \\
0 & 100 & $52 \pm 4$ \\
100 & 100 & $49 \pm 6$ \\
\hline
\end{tabular}

L1210 cells were incubated with specified concentrations of bile acids at $37^{\circ} \mathrm{C}$ for $60 \mathrm{~min}$, then washed and diluted for clonogenic assays. Viability data represent mean \pm S.D. for three assays

Table 2 Effects of extracellular UDCA concentration on distribution ratio and phototoxicity

\begin{tabular}{|c|c|c|c|c|}
\hline \multirow[b]{2}{*}{$\mathrm{UDCA}^{\mathrm{a}}(\mu \mathrm{M})$} & \multirow[b]{2}{*}{$\mathbf{D R}^{\mathbf{b}}$} & \multirow[b]{2}{*}{$\%$ retained $^{\mathbf{c}}$} & \multicolumn{2}{|c|}{$\%$ viability $^{\mathbf{d}}$} \\
\hline & & & No wash & Washed \\
\hline 0 & - & - & $47 \pm 6$ & - \\
\hline 3 & $1.22 \pm 0.03$ & $14 \pm 2.2$ & $43 \pm 3$ & $45 \pm 2$ \\
\hline 10 & $1.19+0.10$ & $13+1.5$ & $27+2$ & $24+1$ \\
\hline 20 & $1.26 \pm 0.09$ & $16 \pm 1.7$ & $21 \pm 2$ & $23 \pm 3$ \\
\hline 30 & $1.35 \pm 0.11$ & $14 \pm 2.0$ & $19 \pm 3$ & $18 \pm 2$ \\
\hline 50 & $1.28+0.12$ & $18+1.9$ & $17+3$ & $16+3$ \\
\hline 70 & $1.31+0.08$ & $16+1.3$ & $13+2$ & $14+1$ \\
\hline 100 & $1.32 \pm 0.13$ & $15 \pm 2.1$ & $10 \pm 2$ & $11 \pm 2$ \\
\hline
\end{tabular}

${ }^{a}$ Extracellular UDCA concentration. ${ }^{b}$ Distribution ratio (intracellular/extracellular). ${ }^{\mathrm{C}} \%$ UDCA retained after a 10 min wash at $37^{\circ} \mathrm{C} .{ }^{\mathrm{d}} \mathrm{Percent}$ viable cells using an $\mathrm{LD}_{50}$ PDT dose with CPO as a function of extracellular UDCA concentration. Data represent mean \pm S.D. for three determinations 

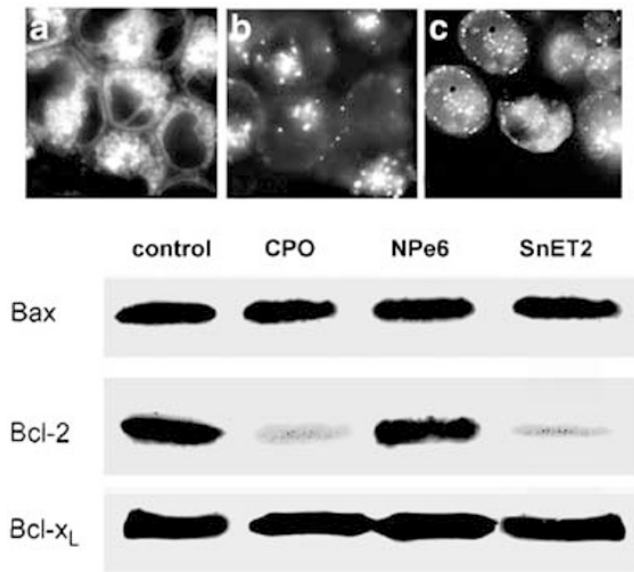

Figure 2 (Top) Localization of photosensitizers in L1210 cells: (a) CPO, (b) NPe6, (c) SnET2. (Bottom) Western blots showing the extent of PDT-induced photodamage to Bax, Bcl-2, Bax or Bcl- $x_{L}$ after $L_{90}$ PDT doses of CPO, NPe6 and SnET2

Table 4 Promotion of PDT efficacy by UDCA

\begin{tabular}{lcr}
\hline & \multicolumn{2}{c}{ Viability (\%) } \\
\cline { 2 - 3 } Photosensitizer & Control & +UDCA \\
\hline None & $98 \pm 1$ & $97 \pm 1$ \\
CPO & $47 \pm 6$ & $9 \pm 3$ \\
NPe6 & $54 \pm 6$ & $53 \pm 5$ \\
SnET2 & $52 \pm 7$ & $11 \pm 4$ \\
\hline
\end{tabular}

Clonogenic assays of $L 1210$ cells photosensitized with specified agents, then irradiated so as to yield an $\mathrm{LD}_{50}$ PDT dose. Effects of adding $100 \mu \mathrm{M}$ UDCA before irradiation are shown. Data represent the mean \pm S.D. for three determinations

morphology, detected by $\mathrm{HO} 342$ labeling (Figure $4 \mathrm{~b}$ ). In the presence of $100 \mu \mathrm{M}$ UDCA, this value increased to $66 \pm 4 \%$ (Figure 4c). This result was not altered when cells were loaded with UDCA $(100 \mu \mathrm{M})$, and then washed for $10 \mathrm{~min}$ at $37^{\circ} \mathrm{C}$ before PDT (Figure 4d). The effect of UDCA on PDT efficacy is therefore not readily reversible. We also measured DEVDase activation $10 \mathrm{~min}$ after irradiation (Table 5). It is noteworthy that loss of $90 \%$ of the initial UDCA pool did not affect the ability of the bile acid to promote DEVDase activation after PDT. Complementary results were obtained in colony-survival assays (Table 2). A dose-response study was carried out using an LD $_{50}$ PDT dose of CPO and graded UDCA levels (Table 2). UDCA-enhanced photokilling was unaffected by a subsequent $10 \mathrm{~min}$ wash at $37^{\circ} \mathrm{C}$, regardless of the initial bile acid concentration.

\section{Effects of UDCA on Bax insertion into the mitochondrial membrane}

We previously reported that PDT conditions sufficient to cause $\mathrm{Bcl}-2$ photodamage markedly promoted the migration of Bax to mitochondria. These latter studies were carried out with murine L1210 leukemia cells and the porphycene CPO. ${ }^{6}$ In the study summarized in Figure 5, we examined the effect

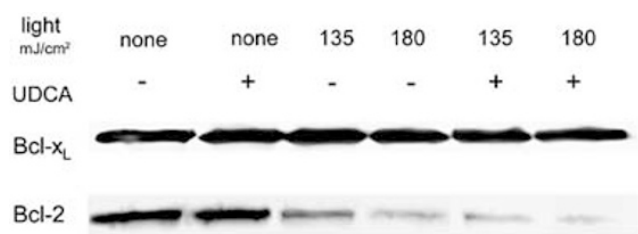

Figure 3 Photodamage to $\mathrm{Bcl}-2$ as a function of the light dose and presence of UDCA. Cells were treated with $2 \mu \mathrm{M} \mathrm{CPO}$ and irradiated with specified light doses $\left(\mathrm{mJ} / \mathrm{cm}^{2}\right)$. UDCA $(100 \mu \mathrm{M})$ was present where specified. Under these conditions, a $135 \mathrm{~mJ} / \mathrm{cm}^{2}$ light dose results in a $50-60 \%$ loss of viability, $180 \mathrm{~mJ} /$ $\mathrm{cm}^{2}$ in a $90-95 \%$ loss of viability
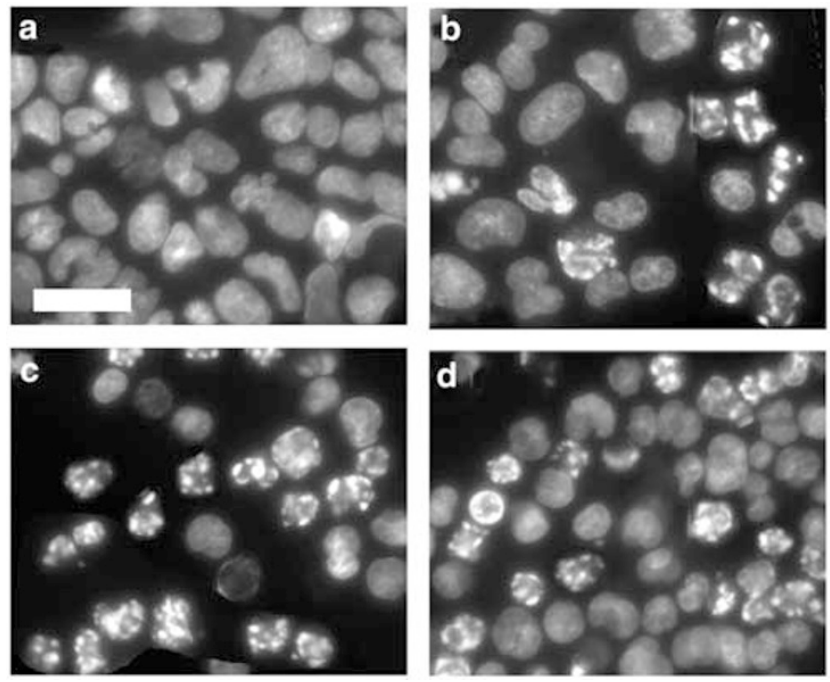

Figure 4 Apoptotic effects of UDCA and PDT. L1210 cells were photosensitized with CPO and irradiated $\left(180 \mathrm{~mJ} / \mathrm{cm}^{2}\right)$, then incubated at $37^{\circ}$ for 60 min and labeled with Höchst dye HO33342: (a) control cells; (b) cells treated with an $\mathrm{LD}_{90}$ PDT dose; (c) effect of $100 \mu \mathrm{M}$ UDCA treatment before PDT as specified in the text; (d) cells treated with UDCA, then washed for $10 \mathrm{~min}$ at $37^{\circ} \mathrm{C}$ before irradiation. White bar $=10 \mu \mathrm{m}$

Table 5 DEVDase activation: effects of PDT and UDCA

\begin{tabular}{lcc}
\hline PDT & UDCA & $\begin{array}{c}\text { DEVDase activity } \\
\text { (nmol/min/mg protein) }\end{array}$ \\
\hline None & None & $0.3 \pm 0.02$ \\
CPO LD 90 & None & $4.7 \pm 0.36$ \\
& $100 \mu \mathrm{M}^{\mathrm{a}}$ & $11.3 \pm 1.19$ \\
& $100 \mu \mathrm{M}^{\mathrm{b}}$ & $10.9 \pm 2.01$ \\
\hline
\end{tabular}

aUDCA present during initial incubation and irradiation. ${ }^{\mathrm{b}} \mathrm{UDCA}$ present during initial incubation, cells washed before irradiation. Data represent the mean \pm S.D. for three determinations

of UDCA alone, and the ability of UDCA to alter the effects of CPO-catalyzed photodamage on the association of Bax with mitochondria. The results indicate a substantial promotion of this association when UDCA is added to a PDT protocol.

\section{Fluorescence polarization}

HA14-1 was initially identified on the basis of its ability to compete with a fluorescent Bak-BH3 peptide (flu-Bak) for 
binding to the surface cleft on Bcl-2, as monitored by fluorescence polarization. ${ }^{19} \mathrm{~A} \mathrm{Bcl}-2$ preparation lacking the C-terminal membrane domain (Bcl-2 $\Delta 21)$ was used in the latter study. Consistent with data described in Wang et al. ${ }^{19}$, we found a significant increase in fluorescence polarization $(P)$ of the flu-Bak peptide upon binding to $\mathrm{Bcl}-2$ (Figure 6$)$. The maximum $P$-value obtained was 0.2 . This increase reflects the decreased mobility of the fluorescent peptide upon binding to a large molecule. Addition of HA14-1 caused a decrease in fluorescence polarization, indicating competition between HA14-1 and flu-Bak for the binding site on Bcl-2. The effect of UDCA on the competition between HA14-1 and flu-Bak for Bcl-2 binding was then examined. In the absence of UDCA, a

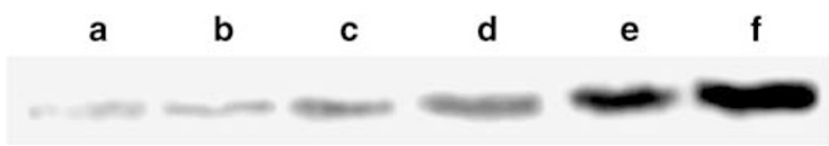

Figure 5 Promotion by UDCA of Bax binding to mitochondria. (a) Control (b) UDCA control, (c) $\mathrm{CPO}+90 \mathrm{~mJ} / \mathrm{cm}^{2}$, (d) $\mathrm{CPO}+180 \mathrm{~mJ} / \mathrm{cm}^{2}$, (e) $\mathrm{CPO}+100 \mu \mathrm{M}$ UDCA $+90 \mathrm{~mJ} / \mathrm{cm}^{2}$, (f) CPO $+100 \mu \mathrm{M}$ UDCA $+180 \mathrm{~mJ} / \mathrm{cm}^{2}$

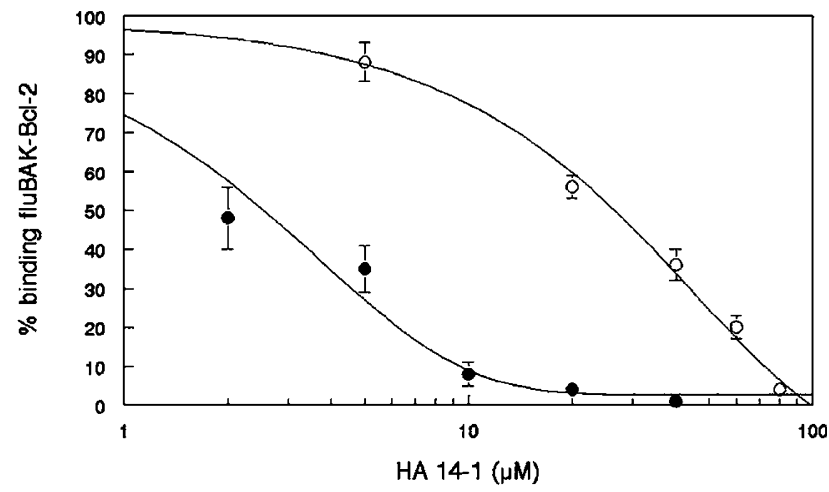

Figure 6 Promotion of binding of HA14-1 to Bcl-2 by UDCA as detected by fluorescence polarization. Bcl-2 221 was incubated with flu-Bak along with graded levels of HA14-1, in the presence or absence of $50 \mu \mathrm{M}$ UDCA, prior to the determination of fluorescence polarization. Data represent mean \pm S.D. of five determinations. $\bigcirc=$ UDCA absent; $\bigcirc=$ UDCA present
$20 \mu \mathrm{M}$ concentration of HA14-1 decreased flu-Bak: Bcl-2 fluorescence polarization binding by half. The corresponding HA14-1 concentration was decreased 10-fold in the presence of $50 \mu \mathrm{M}$ UDCA (Figure 6 ), reflecting a selective promotion of HA14-1 binding to Bcl-2 by the bile acid.

In the absence of HA14-1, the $P$-value for the Bcl-2: flu-Bak complex was unaffected by addition of 50 or $100 \mu \mathrm{M}$ UDCA (not shown). When Bcl-2 was omitted from the system, the $P$ value for flu-Bak was $<0.01$, indicating that the freedom of rotation of the molecule is unrestricted in the absence of a protein. This value was unaffected by addition of UDCA.

\section{Fluorescence resonance energy transfer (FRET) analysis}

FRET occurs when the fluorescence emission spectrum of one fluorophore overlaps the excitation spectrum of the other, and the fluorophores are sufficiently close. ${ }^{22} \mathrm{Bcl}-2$ contains a sufficient number of aromatic amino acids so that it will fluoresce upon excitation at $280 \mathrm{~nm}$. The resulting fluorescence emission spectrum overlaps the excitation spectrum of CPO (Figure 7a). The latter was therefore chosen as the second fluorophore in a FRET study. The hydrophobicity of $\mathrm{CPO}^{23}$ insures that there will be no CPO fluorescence unless the porphycene is bound to a hydrophobic site. In order to examine the possibility that UDCA could promote an interaction between $\mathrm{Bcl}-2$ and a sensitizer in a model membrane system, we embedded $\mathrm{CPO}$ and full-length recombinant $\mathrm{Bcl}-2$ in dioleyl phosphatidylcholine liposomes.

The effects of Bcl-2 and/or UDCA on the fluorescence emission spectrum of CPO embedded in the liposomes (excitation $=400 \mathrm{~nm}$ ) are shown in Figure $7 \mathrm{~b}$. The fluorescence emission intensity of CPO (trace 1) was only slightly promoted by UDCA (trace 2), Bcl-2 (trace 3) or UDCA + Bcl-2 (trace 4). When liposomes contained CPO alone, excitation at $280 \mathrm{~nm}$ resulted in a very slight fluorescence emission at $670 \mathrm{~nm}$, attributed to the long tail of the CPO excitation spectrum into the UV (Figure 7c, trace A, solid line). The fluorescence intensity was not enhanced by addition of an equal volume of $10 \mathrm{mM}$ Triton $\mathrm{X}-100$ detergent, indicating that no CPO remained in an aggregated state outside of the
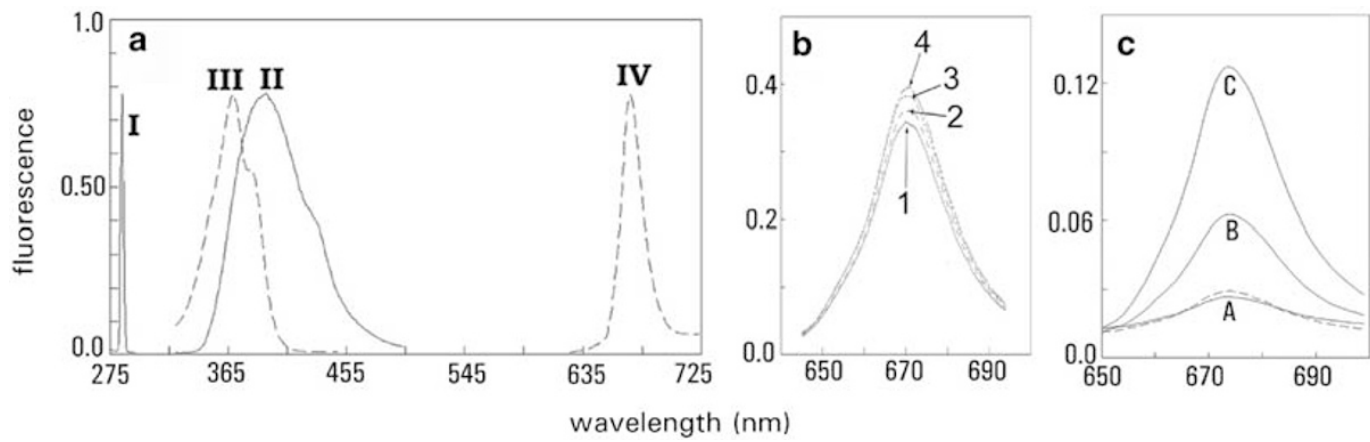

Figure 7 (a) FRET spectral overlap between CPO and Bcl-2. The Bcl-2 excitation spectrum (I) was obtained using $360 \mathrm{~nm}$ emission, and the emission spectrum (II) was acquired with $280 \mathrm{~nm}$ excitation. For CPO, excitation spectrum (III) was obtained using $670 \mathrm{~nm}$ emission, and the emission spectrum (IV) was obtained using $400 \mathrm{~nm}$ excitation. (b) Fluorescence emission spectrum of CPO embedded in dioleyl phosphatldylcholine liposomes (trace 1), after addition of $100 \mu \mathrm{M}$ UDCA (trace 2), after addition of $900 \mathrm{ng} / \mathrm{ml} \mathrm{Bcl}-2$ (trace 3), after addition of UDCA + Bcl-2 (trace 4). Excitation wavelength $=400 \mathrm{~nm}$. (c) Analysis of FRET between CPO and Bcl-2 embedded in dioleyl phosphatidylcholine liposomes. Excitation wavelength $=280 \mathrm{~nm}$. Trace A solid line $=\mathrm{CPO}$ alone; trace $\mathrm{A}$ dashed line $=\mathrm{CPO}+100 \mu \mathrm{M}$ UDCA; Trace $\mathrm{B}=\mathrm{CPO}+900 \mathrm{ng} / \mathrm{ml} \mathrm{Bcl-2;}$ Trace $\mathrm{C}=\mathrm{CPO}, \mathrm{Bcl}-2+100 \mu \mathrm{M}$ UDCA 
liposomes (data not shown). The fluorescence of CPO in a liposomal environment was also unaffected by addition of $100 \mu \mathrm{M}$ UDCA (Figure 7c, trace A, dashed line).

Addition of $\mathrm{Bcl}-2$ to liposomes containing $\mathrm{CPO}$ resulted in a significant promotion of $670 \mathrm{~nm}$ fluorescence (Figure 7c, trace B) upon excitation at $280 \mathrm{~nm}$. We attribute this effect to FRET involving both fluorophores. The FRET signal was further enhanced by addition of $100 \mu \mathrm{M}$ of UDCA (Figure 7c, trace C). The latter result indicates that UDCA has altered the system so as to promote a greater interaction between liposomebound $\mathrm{CPO}$ and $\mathrm{BCl}-2$.

\section{Bcl-2 homodimerization analysis}

An examination of the effect of $100 \mu \mathrm{M}$ UDCA on Bcl-2 homodimer formation was carried out as described by Conus et al. ${ }^{24}$ Gel exclusion chromatography on Superose 12 yielded a single $\mathrm{Bcl}-2$ peak that corresponded to the monomer, molecular weight $=26 \mathrm{kDa}$, whether or not UDCA was present (Figure 8).

\section{Discussion}

Several earlier reports indicated that UDCA could protect cells in culture from the proapoptotic effects of a variety of reagents including more hydrophobic bile acids, for example, DCA. ${ }^{11-15}$ This protective mechanism was attributed to stabilization of the mitochondrial structure, thereby preventing loss of cytochrome $c .{ }^{15}$ Translocation of cytochrome $c$ to the cytosol is known to trigger an apoptotic response via the Apaf-1/caspase-9 pathway. ${ }^{25}$ In contrast, our initial findings identified a different property of UDCA: promotion of apoptotic cell death after photodynamic therapy. ${ }^{18} \mathrm{~A}$ clue concerning the nature of the UDCA effect was provided by the finding that UDCA also enhanced the apoptotic response to the nonpeptidic Bcl-2 antagonist $\mathrm{HA} 14-1 .{ }^{5}$ The implication is that UDCA can magnify effects of $\mathrm{Bcl}-2$ inactivating procedures.

Competition studies (Table 1) showed no effect of an equimolar concentration of nonradioactive UDCA or DCA on

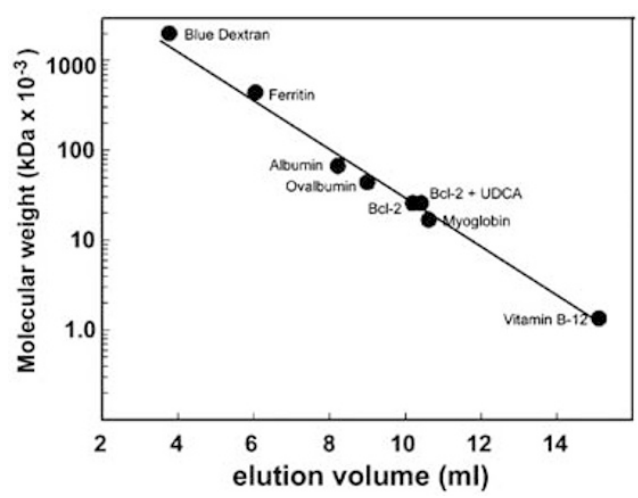

Figure 8 Elution pattern of marker proteins and Bcl-2 from a Superose 12 column. Proteins were detected by measurement of $280 \mathrm{~nm}$ absorbance except for $\mathrm{Bcl}-2$, which was detected using the fluorescence probe NanoOrange, as described in the text accumulation or stability of ${ }^{14} \mathrm{C}$-DCA or -UDCA pools. These results indicate that $\mathrm{L} 1210$ cells have a high capacity for bile acid accumulation. Washout experiments revealed that $90 \%$ of the initial UDCA or DCA was rapidly lost during a subsequent wash. Such a loss did not affect the ability of UDCA to promote the apoptotic response to PDT (Figure 4, Table 2), indicating that the proapoptotic effect of UDCA is at least temporarily irreversible. Moreover, UDCA did not protect L1210 cells from the toxic effects of DCA (Table 3 ). This result is consistent with other reports indicating that UDCA does not always offer protection from toxic effects of more hydrophobic bile acids. ${ }^{16,17}$

Our initial photodynamic studies with UDCA utilized SnET2, a photosensitizing agent that has a broad localization pattern (Figure 2, top). In this study, we examined two photosensitizing agents, NPe6 and CPO, with more selective targets. UDCA did not promote the phototoxic effect of NPe6 (Table 4), a sensitizer that localizes to lysosomes (Figure 2, top). Upon irradiation of NPe6-sensitized cells, the ensuing lysosomal photodamage ultimately leads to Bid cleavage, activation of procaspases-9 and -3 , and an apoptotic outcome. ${ }^{26,27}$ This pathway does not directly involve $\mathrm{Bcl}-2$, and no $\mathrm{Bcl}-2$ photodamage was observed after NPe6 photodamage (Figure 2, bottom). In contrast, the photosensitizer CPO, an agent that localizes in subcellular membranes (Figure 2), catalyzed substantial Bcl-2 photodamage (Figure 2, bottom). Both the phototoxicity of CPO and its ability to cause $\mathrm{Bcl}-2$ photodamage were enhanced by UDCA (Figure 3, Table 4). These results indicate that the ability of UDCA to enhance the apoptotic response to SnET2 also derives from Bcl-2 photodamage.

In the presence of UDCA, Bcl-2 photodamage was enhanced (Figure 3). Even at an LD 90 PDT dose, the Western blot indicated that some $\mathrm{Bcl}-2$ remained undamaged. In this regard, Usuda et al. ${ }^{28}$ have shown that a minor degree of photodamage to $\mathrm{Bcl}-2$ can interfere with its anti-apoptotic function.

Results shown in Figure 6 suggest an explanation for the ability of UDCA to promote HA14-1-induced apoptosis described in Kessel et al. ${ }^{5}$ Fluorescence polarization studies show that UDCA increases the affinity of HA14-1 for the surface cleft in the Bcl-2 protein, as indicated by an enhanced ability to displace flu-Bak from this site, resulting in a decrease in $P$. This effect can be explained if we postulate that UDCA alters the conformation of the $\mathrm{Bcl}-2$ molecule so as to promote HA14-1 binding. Furthermore, this result demonstrates that UDCA preferentially promotes HA14-1 binding to $\mathrm{Bcl}-2$. If binding of flu-Bak were similarly enhanced, we would observe no difference in flu-Bak fluorescence polarization in the presence of UDCA. A conformational change in Bcl-2, upon exposure to UDCA, can also explain enhanced Bcl-2 photodamage (see below).

We previously reported the effects of graded levels of UDCA on HA14-1 dose-dependent cytotoxicity and DEVDase activation. ${ }^{5}$ In the latter study, only extracellular levels of UDCA were reported. Data obtained in the current study using radioactive UDCA show that the pool of UDCA stable to washing is $\sim 10-15 \%$ of the initial intracellular level (Table 1 ). Nevertheless, this pool was sufficient for enhanced DEVDase activation (Table 5) and photokilling (Table 2). It is not clear 
whether this represents an irreversible consequence of an initially high concentration of intracellular UDCA, or the effect of a persisting stable pool of the bile acid.

Data shown in Figure 2 indicate that $\mathrm{Bcl}-\mathrm{x}_{\mathrm{L}}$ photodamage does not occur with either CPO or SnET2. Oleinick had initially reported a similar result ${ }^{4}$ using a different photosensitizer, but later found that with a different antibody $\mathrm{Bcl}-\mathrm{x}_{\mathrm{L}}$ photodamage was observed. ${ }^{29}$ It is possible that $\mathrm{Bcl}-\mathrm{x}_{\mathrm{L}}$ is located in $\mathrm{L} 1210$ cells at sites where binding of CPO and SnET2 is minimal. A study involving the photosensitizing agent protoporphyrin, derived from 5-aminolevulinic acid administration, indicated that $\mathrm{Bcl}-2$ was more sensitive to photodamage than $\mathrm{BCl}-\mathrm{x}_{\mathrm{L}} \cdot{ }^{30}$

With regard to the determinants of Bcl-2 photodamage, it is clear from the work of Usuda et al. ${ }^{7}$ that only proteins in very close proximity to sites of photosensitizer localization will be targets for photodamage. Studies with the photosensitizer Pc 4 demonstrated that a mutant Bcl-2 lacking the transmembrane domain, and therefore confined to the cytosol, was protected from photodamage. ${ }^{7}$ We therefore propose that the enhanced $\mathrm{Bcl}-2$ photodamage that occurs in the presence of UDCA reflects a conformational change in $\mathrm{Bcl}-2$ that enhances its proximity to membrane-bound photosensitizer. We sought proof for this hypothesis by designing a liposomal system to examine fluorescence resonance energy transfer between embedded Bcl-2 and an appropriate fluorophore.

In the current studies the ideal acceptor fluorophore for FRET studies should have an excitation spectrum that overlaps the fluorescence emission of $\mathrm{Bcl}-2$. The emission spectrum should also show a significant Stokes shift, so that the probe emission will be well separated from the excitation wavelength. The spectral properties of CPO fit these requirements (Figure $7 \mathrm{a}$ ). While $\mathrm{CPO}$ is a photosensitizing agent, the light intensity used in FRET studies is several orders of magnitude below the level needed to cause photodamage.

When liposomes containing CPO alone were excited at $280 \mathrm{~nm}$, there was a low level of fluorescence emission at $670 \mathrm{~nm}$, reflecting the tail of the excitation curve of $\mathrm{CPO}$ (Figure 7c). Addition of Triton X-100 or UDCA did not alter the intensity of fluorescence indicating that there was no free $\mathrm{CPO}$ in the system, and that UDCA did not affect affinity of CPO for liposomes. Addition of Bcl-2 resulted in a substantial promotion of $670 \mathrm{~nm}$ fluorescence, and this was further enhanced by addition of $100 \mu \mathrm{M}$ UDCA. These results indicate that $\mathrm{Bcl}-2$ binds sufficiently close to liposomal sites of CPO so that FRET can take place, and that addition of UDCA results in yet closer contact between fluorogenic amino acids in the protein and liposome-bound CPO.

Hanada et al. ${ }^{31}$ reported homodimerization of $\mathrm{Bcl}-2$, but Conus et al. ${ }^{24}$ were unable to confirm this observation and attributed the earlier observation to the use of a disrupted $\mathrm{Bcl}-$ 2 structure. Xie et al. ${ }^{32}$ observed homodimers of a related protein, $\mathrm{Bcl}-\mathrm{x}_{\mathrm{L}}$, but this required the presence of $0.1 \%$ Tween 20. Using the gel exclusion chromatography system described by Conus et al., we found no evidence for the presence of $\mathrm{Bcl}-2$ dimers under our experimental conditions, whether or not $100 \mu \mathrm{M}$ UDCA was present. Moreover, we found no effects of UDCA on the fluorescence polarization of the flu-Bak peptide when bound to Bcl-2.
Steer's ${ }^{33}$ group recently reported that UDCA can prevent insertion of recombinant Bax into isolated rat liver mitochondria, thereby providing a mechanism for protection from apoptosis by UDCA. In studies to be reported elsewhere, we could not duplicate this effect with L1210 cells and recombinant Bax, unless the Bax was first 'activated', ${ }^{34}$ that is, by exposure to octyl glucoside. The 'protective' effect of UDCA on mitochondria must either be unique to a cell-free system, or a relatively minor effect, compared with the proapoptotic effects of UDCA in cell lines examined here and described in Kessel et al. ${ }^{18}$ The fluorescence polarization results are consistent with the hypothesis that UDCA initiates a conformational change that promotes binding of HA14-1 to Bcl-2. We propose that this change also leads to an increased sensitivity of $\mathrm{Bcl}-2$ to photodamage by promoting proximity to membrane-bound CPO.

It is noteworthy that cell viability was not affected by $100 \mu \mathrm{M}$ UDCA alone (Table 3), indicating that the postulated UDCAinduced change in $\mathrm{Bcl}-2$ conformation has no long-term consequences unless a proapoptotic stimulus, for example, $\mathrm{HA} 14-1$ or Bcl-2 photodamage, is present. The proposed mechanism of action for UDCA predicts that this bile acid will promote PDT efficacy in vivo without adverse effects on the host. The results of a recent study involving a transplantable mouse tumor ${ }^{35}$ have confirmed this supposition.

\section{Materials and Methods}

\section{Drugs and chemicals}

The porphycene $\mathrm{CPO}^{6,23}$ was obtained from Dr. Alex Cross, CytoPharm, San Francisco CA, USA. Both $\mathrm{SnET}^{36}$ and the water-soluble chlorin $\mathrm{NPe}^{37}$ were provided by Drs. Kevin Smith and Graça Vicente, Department of Chemistry, Louisiana State University in Baton Rouge. CPO and SnET2 were dissolved in DMSO to obtain $1 \mathrm{mM}$ stock solutions. Stock solutions $(200 \mathrm{mM})$ of UDCA and DCA (Sigma Chemical Co., St. Louis, MO, USA) were prepared in $200 \mathrm{mM} \mathrm{NaOH}$.

\section{Radioactive DCA and UDCA}

The procedures outlined in Matern et al..$^{38}$ and Tserng and Klein ${ }^{39}$ were followed, with minor modifications, to prepare UDCA and DCA labeled with ${ }^{14} \mathrm{C}$ in the terminal $\mathrm{COOH}$ (Figure 1). UDCA or DCA $(5 \mathrm{~g})$ were converted to the corresponding formyl derivatives by treatment with $20 \mathrm{ml}$ of $90 \%$ formic acid $+0.5 \mathrm{ml}$ of $70 \% \mathrm{HClO}_{4}$. After heating to $55^{\circ} \mathrm{C}$ for $1.5 \mathrm{~h}$, the solution was cooled to $40^{\circ} \mathrm{C}$ and acetic anhydride added dropwise, maintaining a temperature of $50-55^{\circ} \mathrm{C}$, until a substantial evolution of $\mathrm{CO}_{2}$ was observed. The resulting mixture was allowed to cool and then poured into $200 \mathrm{ml}$ of cold water. The formylated product was recovered by filtration, washed with water until the odor of acetic anhydride could no longer be detected, and dried over $\mathrm{P}_{2} \mathrm{O}_{5}$ in a vacuum desiccator.

The formylated bile acid (1 gm) was dissolved in $35 \mathrm{ml}$ of benzene and dried azeotropically. Since Kochi ${ }^{40}$ reported that traces of water did not interfere with the subsequent lead tetraacetate oxidation, azeotropic distillation was limited to $30 \mathrm{~min}$. The solution was then cooled to room temperature and $2.2 \mathrm{~g}$ of lead tetraacetate $+200 \mathrm{mg}$ of anhydrous $\mathrm{LiCl}$ added with constant stirring. The solution was immediately degassed with nitrogen (critical for a good yield), and heated under reflux for $6 \mathrm{~h}$. During this time, additional $200 \mathrm{mg}$ portions of $\mathrm{LiCl}$ were added at $1 \mathrm{~h}$ intervals. The solution was then stirred for $16 \mathrm{~h}$ at room temperature, filtered, and the 
filtrate was washed three times with $10 \mathrm{ml}$ of $2 \% \mathrm{NaOH}$, four times with water and dried over anhydrous $\mathrm{MgSO}_{4}$. The product was evaporated to dryness in vacuum, taken up in $10 \mathrm{ml}$ of absolute ethanol, evaporated under vacuum until crystals began to form, and then stored at $-20^{\circ}$ overnight. The yield of the chloro-diformylnorcholanes was $60-65 \%$.

Conversion of the norcholanes to ${ }^{14} \mathrm{C}-\mathrm{UDCA}$ and $-\mathrm{DCA}$ was carried out by Moravec Biochemicals Inc., Brea, CA. USA. This involved heating a stirred suspension of $50 \mathrm{mg}$ of the bile acid $+1 \mathrm{mCi}$ of $\mathrm{Na}^{14} \mathrm{CN}(500 \mathrm{mg})$ in $5 \mathrm{ml}$ of dimethylformamide at $110^{\circ} \mathrm{C}$ for $5.5 \mathrm{~h}$. After cooling to room temperature, $20 \mathrm{ml}$ of water was added and the precipitated nitrile was removed by centrifugation. The product was dissolved in $5 \mathrm{ml}$ of hot ethanol, and a solution of $630 \mathrm{mg}$ of $\mathrm{NaOH}$ in $5 \mathrm{ml}$ of water was added. The mixture was heated under reflux for $40 \mathrm{~h}$, cooled and washed with ether. Residual ether was removed by brief heating, and the filtrate acidified with $1 \mathrm{M} \mathrm{HCl}$ to precipitate the ${ }^{14} \mathrm{C}$ bile acid. After washing with water, the product was recrystallized from 2-propanol. Specific activities of 50 $55 \mu \mathrm{Ci} / \mathrm{mmol}$ were obtained. At each step in the reaction process, we confirmed that NMR and mass spectroscopy data (kindly performed by Professor M Graça Vicente, Department of Chemistry, Louisiana State University) were consistent with the expected products.

\section{Cells and cell culture}

Murine L1210 cells were maintained in culture using Fischer's growth medium $+10 \%$ horse serum, $1 \mathrm{mM}$ glutathione, $1 \mathrm{mM}$ mercaptoethanol and gentamicin. Since Fischer's medium is no longer available, we supplemented $\alpha$-MEM (GIBCO-BRL, Grand Island, NY, USA) to achieve the original Fischer's formulation. This involved addition of $\mathrm{MgCl}_{2}$ $(45 \mathrm{mg} / \mathrm{l})$, methionine $(75 \mathrm{mg} / \mathrm{l})$, phenylalanine $(30 \mathrm{mg} / \mathrm{l})$, valine $(30 \mathrm{mg} / \mathrm{l})$ and folic acid $(9 \mathrm{mg} / \mathrm{l})$.

\section{Intracellular accumulation of bile acids}

L1210 cells were incubated in growth medium containing $100 \mu \mathrm{M}$ radioactive DCA or UDCA for $1-30 \mathrm{~min}$ at $37^{\circ} \mathrm{C}$, and then washed with cold isotonic $\mathrm{NaCl}$. Radioactivity was assessed by solubilizing cell pellets and determining radioactivity by scintillation counting. In some studies, nonradioactive DCA or UDCA was added $10 \mathrm{~min}$ before the radioactive substrates. In another series of studies, the cells were incubated with radioactive bile acids, and then washed in fresh medium for 10-30 min at $37^{\circ} \mathrm{C}$ to determine the stability of bile acid pools.

\section{PDT protocols}

Suspensions of L1210 cells $\left(7 \mathrm{mg} / \mathrm{ml}\right.$ wet weight $=2 \times 10^{6}$ cells) were incubated in growth medium containing $2 \mu \mathrm{M}$ CPO or SnET2 for 15 min at $37^{\circ} \mathrm{C}$, or with $60 \mu \mathrm{M} \mathrm{NPe} 6$ for $4 \mathrm{~h}$. The cells were subsequently washed and resuspended in fresh growth medium at room temperature. Irradiation was provided by a $600 \mathrm{~W}$ quartz-halogen source filtered with $10 \mathrm{~cm}$ of water and an $800 \mathrm{~nm}$ cutoff filter to remove IR. Bandwidth was further confined to $660 \pm 10 \mathrm{~nm}(\mathrm{SnET} 2, \mathrm{NPe}$ ) or $610 \pm 10 \mathrm{~nm}$ (CPO) by narrowband interference filters (Oriel, Stratford, CT, USA). The total light dose is specified for each experiment. Initial experiments indicated that a $90 \%$ loss of L1210 cell viability was produced by irradiation with $180 \mathrm{~mJ} / \mathrm{cm}^{2}$ with $\mathrm{CPO}, 350 \mathrm{~mJ} / \mathrm{cm}^{2}$ with NPe6 and $135 \mathrm{~mJ} / \mathrm{cm}^{2}$ with SnET2. Different light doses were used in these experiments, as indicated above.

In some studies, cells were loaded with $100 \mu \mathrm{M}$ UDCA and/or photosensitizer for $30 \mathrm{~min}$ prior to irradiation to assess the proapoptotic effects of the combination. To assess the reversibility of the UDCA effect, cells were incubated with the bile acid, then washed for $10 \mathrm{~min}$ at $37^{\circ} \mathrm{C}$ before loading with CPO and subsequent irradiation. Intracellular levels of UDCA were measured before and after washing over a range of drug levels $(3-100 \mu \mathrm{M})$. Effects of washing on the subsequent ability of an $\mathrm{LD}_{50}$ PDT dose with CPO were also determined.

\section{DEVDase assay}

Cells were collected at varying times after PDT, washed and lysed in $200 \mu$ l of buffer containing $50 \mathrm{mM}$ Tris pH 7.2, 0.03\% Nonidet P-40 and $1 \mathrm{mM}$ DTT. The lysate was briefly sonicated and the debris removed by centrifugation at $10000 \times g$ for $1 \mathrm{~min}$. The supernatant fluid $(100 \mu \mathrm{l})$ was mixed with $40 \mu \mathrm{M}$ DEVD-R110, $10 \mathrm{mM}$ HEPES pH 7.5, $50 \mathrm{mM} \mathrm{NaCl}$ and $2.5 \mathrm{mM} \mathrm{DTT}$ in a total volume of $200 \mu \mathrm{l}$. The rate of increase in fluorescence emission, resulting from the release of rhodamine-110 from the fluorogenic substrate, ${ }^{5,6}$ was measured over $30 \mathrm{~min}$ at room temperature, using a fluorescence plate reader.

DEVDase activity is reported in terms of $\mathrm{nmol}$ product $/ \mathrm{min} / \mathrm{mg}$ protein. Control determinations were made on extracts of untreated cells. Each assay was performed with triplicate samples. The BioRad assay, using BSA as a standard, was used to estimate protein concentrations.

\section{Western blots}

L1210 cells were processed as described previously for Western blot analysis of $\mathrm{Bax}, \mathrm{Bcl}-2, \mathrm{Bax}$ or $\mathrm{Bcl}-\mathrm{x}_{\mathrm{L}}$ levels. ${ }^{5}$ Equal protein amounts were loaded into each lane of the gels as determined by the BioRad procedure.

\section{Viability studies}

Cells were incubated for $60 \mathrm{~min}$ at $37^{\circ} \mathrm{C}$ in growth medium containing $100 \mu \mathrm{M}$ DCA or UDCA. In attempts to reverse DCA toxicity, cells were incubated with $100 \mu \mathrm{M} \mathrm{DCA}+3-100 \mu \mathrm{M}$ UDCA. The cells were then washed and used for a clonogenic growth assay.

\section{Effects of UDCA on Bax association with mitochondria}

L1210 cells were loaded with $2 \mu \mathrm{M} \mathrm{CPO}$ in the presence or absence of $100 \mu \mathrm{M}$ UDCA for $30 \mathrm{~min}$ at $37^{\circ} \mathrm{C}$. Cells were then washed, irradiated for varying lengths of time and then incubated at $37^{\circ} \mathrm{C}$ for an additional $30 \mathrm{~min}$. A nitrogen cavitation technique ${ }^{41}$ was used to rupture the cell membrane, and mitochondria were collected at $1000 \times \mathrm{g}$. Mitochondria were resuspended in lysis buffer and frozen. Proteins were separated on a $12 \%$ SDS-PAGE gel. After electrophoresis, the separated proteins were transferred to a PVDF membrane, blocked and incubated with a Bax antibody (PharMingen, product No. 554106). The membrane was subsequently incubated with an appropriate secondary antibody, and developed with an ECF Western blotting kit (Amersham Pharmacia) for analysis by fluorescence.

\section{Fluorescence microscopy}

Localization of SnET2, CPO and NPe6 in L1210 cells was determined after incubations with the drug levels described in the PDT protocol. A Nikon E600 series microscope was employed using $360-450 \mathrm{~nm}$ excitation, with fluorescence emission measured at $600-700 \mathrm{~nm}$. For the detection of apoptotic nuclei, cells were loaded with drugs, washed and irradiated as described above, then diluted to a density of $4 \times 10^{5} / \mathrm{ml}$ and incubated for $60 \mathrm{~min}$ at $37^{\circ} \mathrm{C}$. Thereafter, cells were collected and labeled 
with $\mathrm{HO} 342(2 \mu \mathrm{g} / \mathrm{ml})$. A more detailed description is provided in Kessel et al. ${ }^{5}$ After $5 \mathrm{~min}$ at $37^{\circ} \mathrm{C}$, the cells were collected by centrifugation and the percentage of apoptotic nuclei were determined by fluorescence microscopy (three fields of 100 cells each). HO342 fluorescence (420$450 \mathrm{~nm}$ ) was detected upon excitation at $330-380 \mathrm{~nm}$. A SenSys CCD camera (Photometrics) was used for image acquisition, and the resulting data were processed using MetaMorph software (Universal Imaging, Downingtown, PA, USA).

\section{Fluorescence polarization}

The binding affinity of organic compounds to Bcl-2 protein in vitro was determined by a competitive binding assay based on fluorescence polarization. The substrate was 5-carboxyfluorecein coupled to the $\mathrm{N}$ terminus of a peptide, GQVGRQLAIIGDDINR, derived from the BH3 domain of Bak (flu-Bak). This sequence has been shown to bind to the surface pocket of the $\mathrm{Bcl}-\mathrm{x}_{\mathrm{L}}$ protein with high-affinity. ${ }^{19}$ The $\mathrm{Bcl}-2$ used in studies reported in Wang et al. ${ }^{19}$ was a recombinant GST-fused soluble protein lacking the C-terminal membrane-traversing region (Bcl-2 $\Delta 21$, Santa Cruz Biotechnology). We used a similar product provided by $R \& D$ Systems Inc, Minneapolis, MN, USA.

A mixture of $150 \mathrm{nM}$ flu-Bak peptide (Peptidogenic Research, Livermore, CA, USA) and $280 \mathrm{nM} \mathrm{Bcl-2}$ protein, containing HA14-1 and/ or UDCA where specified, was incubated for $30 \mathrm{~min}$ at room temperature in $20 \mathrm{mM}$ phosphate buffer $\mathrm{pH} 7.4$ containing $50 \mathrm{mM} \mathrm{NaCl}$ and $1 \mathrm{mM}$ EDTA. Binding of flu-Bak to Bcl-2 protein was measured with an LS-50 luminescence spectrometer equipped with polarizers, using a dual path length quartz cell (Perkin-Elmer). The fluorophore was excited with vertical polarized light at $480 \mathrm{~nm}$ (excitation slit width $15 \mathrm{~nm}$ ), and the polarization value of the emitted light was observed through vertical and horizontal polarizers at $530 \mathrm{~nm}$ (emission slit width $15 \mathrm{~nm}$ ). The binding affinity of HA14-1 for Bcl-2 was assessed by determining the ability of graded concentrations of the compound to inhibit flu-Bak binding to Bcl-2. Additional controls were carried out using fluorescein and flu-Bak in the presence versus absence of UDCA to assess the polarization of fluorescence in the absence of $\mathrm{Bcl}-2$.

\section{FRET analysis}

These studies were carried out with full-length recombinant $\mathrm{Bcl}-2$ generated by C\&P Biotech Corp., Thornhill, Ontario, using cDNA provided by Dr. Stan Korsmeyer, Harvard Medical School. Dioleyl phosphatidylcholine liposomes were prepared as described in Schendel and Reed ${ }^{42}$, using a buffer composed of $125 \mathrm{mM}$ sucrose $+10 \mathrm{mM}$ HEPES, pH 7.4. After evaporation of the solvent, the phospholipid residue was taken up in buffer, degassed with nitrogen and sonicated in a G112SP1 ultrasonic bath (Laboratory Supplies Inc., Hicksville, NY, USA) under nitrogen, until the solution was clear. An SLM 48000 instrument was used for acquisition of fluorescence spectra. FRET analysis was carried out by excitation at $280 \mathrm{~nm}$, and the fluorescence emission spectra $(625-675 \mathrm{~nm})$ was recorded. Liposomes were incubated with $1 \mu \mathrm{M} \mathrm{CPO}$ for $10 \mathrm{~min}$ at room temperature at which time the fluorescence intensity of CPO emission $(670 \mathrm{~nm})$ had reached a steady state (excitation $=400 \mathrm{~nm})$. Additional studies were carried out using Bcl-2 $(900 \mathrm{ng} / \mathrm{ml})$ or CPO embedded in the liposomal preparation. In all such studies, the liposomal mixtures were held at room temperature for $10 \mathrm{~min}$ at which time a steady state was reached. Effects of Bcl-2 and/or UDCA on the fluorescence emission spectrum of CPO were determined using $400 \mathrm{~nm}$ excitation.

\section{Effects of UDCA on Bcl-2 homodimerization}

$\mathrm{Bcl}-2$ dimerization was assessed by gel exclusion chromatography using a $0.8 \times 25 \mathrm{~cm}^{2}$ Superose 12 column as described by Conus et al. ${ }^{24}$ The column was calibrated with a series of standards, which were detected by monitoring absorbance at $280 \mathrm{~nm}$. Bcl-2 protein was detected using the NanoOrange reagent marketed by Molecular Probes, Eugene, OR, USA. Eluted fractions were mixed with NanoOrange and then heated to $90^{\circ} \mathrm{C}$ for $10 \mathrm{~min}$, to denature proteins. Fluorescence was then read using a CCD camera and multichannel analyzer. Upon excitation at $470 \mathrm{~nm}$, a fluorescence peak at $\sim 570 \mathrm{~nm}$ was recorded. To test the effect of UDCA on the elution profile, the column was equilibrated in a buffer containing $100 \mu \mathrm{M}$ UDCA prior to the addition of a $\mathrm{Bcl}-2$ preparation that also contained UDCA. The bile acid had no effect on the fluorescence emission intensity of NanoOrange.

\section{Acknowledgements}

We thank Ann Marie Santiago and Brendan Leeson for excellent technical assistance. This study was supported by grants CA 92618, CA 23378 and ES009392 from the $\mathrm{NIH}$ and utilized the services of the Protein Interactions and Proteomics Facility Core, which is funded by P30 ES006639 from NIEHS.

\section{References}

1. Dougherty TJ, Gomer CJ, Henderson BW, Jori G, Kessel D, Korbelik M, Moan J and Peng Q (1998) Photodynamic therapy. J. Natl. Cancer Inst. 90: 889-905

2. Kim HR, Luo Y, Li G and Kessel D (1999) Enhanced apoptotic response to photodynamic therapy after Bcl-2 transfection. Cancer Res. 59: 3429-3432

3. Kessel D, Luo Y, Deng Y and Chang CK (1997) The role of subcellular localization in initiation of apoptosis by photodynamic therapy. Photochem. Photobiol. 65: 422-426

4. Xue LY, Chiu SM and Oleinick NL (2001) Photochemical destruction of the Bcl2 oncoprotein during photodynamic therapy with the phthalocyanine photosensitizer Pc 4. Oncogene 20: 3420-3427

5. Kessel D, Castelli M and Reiners Jr JJ (2002) Apoptotic response to photodynamic therapy versus the Bcl-2 antagonist HA14-1. Photochem. Photobiol. 76: 314-319

6. Kessel D and Castelli M (2001) Evidence that Bcl-2 is the target of three photosensitizers that induce a rapid apoptotic response. Photochem. Photobiol. 74: 318-322

7. Usuda J, Chiu SM, Murphy ES, Lam M, Nieminen A and Oleinick NL (2003) Domain-dependent photodamage to $\mathrm{Bcl}-2$ : a membrane-anchorage region is needed to form the target of phthalocyanine photosensitization. J. Biol. Chem. 278: 2021-2029

8. Ljubuncie P, Fuhrman B, Oiknine J, Aviram M and Bomzon A (1996) Effect of deoxycholic acid and ursodeoxycholic acid on lipid peroxidation in cultured macrophages. Gut 39: 475-478

9. Mitsuyoshi H, Nakashima T, Sumida Y, Yoh T, Nakajima Y, Ishikawa H, Inaba K, Sakamoto Y, Okanoue T and Kashima K (1999) Ursodeoxycholic acid protects hepatocytes against oxidative injury via induction of antioxidants. Biochem. Biophys. Res. Commun. 263: 537-542

10. Nguyen TD, Oliva L, Villard PH, Puyoou F, Sauze C, Montet AM, Lacarelle B, Durand A and Montet JC (1999) CYP2E1 and CYP3A1/2 gene expression is not associated with the ursodeoxycholate effect on ethanol-induced lipoperoxidation. Life Sci. 65: 1103-1113

11. Rodrigues CM, Fan G, Wong PY, Kren BT and Steer CJ (1998) Ursodeoxycholic acid may inhibit deoxycholic acid-induced apoptosis by modulating mitochondrial transmembrane potential and reactive oxygen species production. Mol. Med. 4: 165-178

12. Rodrigues CM, Ma X, Linehan-Stieers C, Fan G, Kren BT and Steer CJ (1999) Ursodeoxycholic acid prevents cytochrome $c$ release in apoptosis by inhibiting 
mitochondrial membrane depolarization and channel formation. Cell Death Differ. 6: 842-854

13. Rodrigues CM, Fan G, Ma X, Kren BT and Steer CJ (1998) A novel role for ursodeoxycholic acid in inhibiting apoptosis by modulating mitochondrial membrane perturbation. J. Clin. Invest. 101: 2790-2799

14. Rodrigues CM and Steer CJ (2001) The therapeutic effects of ursodeoxycholic acid as an anti-apoptotic agent. Expert Opin. Invest. Drugs 10: 1243-1253

15. Botla R, Spivey JR, Aguilar H, Bronk SF and Gores GJ (1995) Ursodeoxycholate (UDCA) inhibits the mitochondrial membrane permeability transition induced by glycochenodeoxycholate: a mechanism of UDCA cytoprotection. J. Pharmacol. Exp. Ther. 272: 930-938

16. Rolo AP, Palmeira CM and Wallace KB (2002) Interactions of combined bile acids on hepatocyte viability: cytoprotection or synergism. Toxicol. Lett. 126: 197-203

17. Schlottman K, Wachs FP, Krieg RC, Kullmann F, Scholmerich J and Rogler G (2000) Characterization of bile salt-induced apoptosis in colon cancer cell lines. Cancer Res. 60: 4270-4276

18. Kessel D, Caruso JA and Reiners Jr JJ (2000) Potentiation of photodynamic therapy by ursodeoxycholic acid. Cancer Res. 60: 6985-6988

19. Wang JL, Liu D, Zhang ZJ, Shan S, Han X, Srinivasula SM, Croce CM, Alnemri ES and Huang Z (2000) Structure-based discovery of an organic compound that binds Bcl-2 protein and induces apoptosis of tumor cells. Proc. Natl. Acad. Sci. USA 97: 7124-7129

20. Liu D and Huang $Z$ (2001) Synthetic peptides and non-peptidic molecules as probes of structure and function of $\mathrm{Bcl}-2$ family proteins and modulators of apoptosis. Apoptosis 6: 453-462

21. Wilton JC, Matthews GM, Burgoyne RD, Mills CO, Chipman JK and Coleman R (1994) Fluorescent choleretic and cholestatic bile salts take different paths across the hepatocyte:transcytosis of glycolithocholate leads to an extensive redistribution of annexin II. J. Cell Biol. 127: 401-410

22. Heyduk T (2002) Measuring protein conformational changes by FRET/LRET. Curr. Opin. Biotechnol. 3: 292-296

23. Toledano H, Edrei R and Kimel S (1998) Photodynamic damage by liposomebound porphycenes: comparison between in vitro and in vivo models. J. Photochem. Photobiol. B 42: 20-27

24. Conus S, Kaufmann T, Fellay I, Otter I, Rosse T and Borner C (2000) Bcl-2 is a monomeric protein: prevention of homodimerization by structural constraints. EMBO J. 19: 1534-1544

25. Budihardjo I, Oliver H, Lutter M, Luo X and Wang X (1999) Biochemical pathways of caspase activation during apoptosis. Annu. Rev. Cell Dev. Biol. 15 269-290

26. Kessel D, Luo Y, Mathieu P and Reiners Jr JJ (2000) Determinants of the apoptotic response to lysosomal photodamage. Photochem. Photobiol. 71: 196-200

27. Reiners Jr JJ, Caruso JA, Mathieu $P$, Chelladurai $B$, Yin XM and Kessel $D$ (2002) Release of cytochrome $C$ and activation of pro-caspase-9 following lysosomal photodamage involves Bid cleavage. Cell Death Differ. 9: 934-944
28. Usuda J, Xue L-Y, Chio S-M, Azizuddin K, Morris RL, Mulvihill J and Oleinick NO (2003) From molecular PDT damage to cell and tumor responses: attempts at bridging the gap on the role of Bcl-2. Proc. SPIE 4952: 1-9

29. Xue L, Chiu S-M, Fiebig A, Andrews DW and Oleinick NO (2003) Photodamage to multiple $\mathrm{Bcl}-\mathrm{xL}$ isoforms by photodynamic therapy with the phthalocyanine photosensitizer Pc 4. Oncogene 22: 9197-9204

30. Grebenova D, Kuzelova K, Smetana K, Pluskalova M, Cajthamlova H, Marinov I, Fuchs O, Soucek J, Jarolim P and Hrkal Z (2003) Mitochondrial and endoplasmic reticulum stress-induced apoptotic pathways are activated by 5 aminolevulinic acid-based photodynamic therapy in HL60 leukemia cells. J. Photochem. Photobiol. B 69: 71-85

31. Hanada M, Aime-Sempe C, Sato T and Reed JC (1995) Structure-function analysis of $\mathrm{Bcl}-2$ protein. Identification of conserved domains important for homodimerization with $\mathrm{Bcl}-2$ and heterodimerization with Bax. J. Biol. Chem. 270: 11962-11969

32. Xie Z, Schendel S, Matsuyama S and Reed JC (1998) Acidic pH promotes dimerization of $\mathrm{Bcl}-2$ family proteins. Biochemistry 37 : 6410-6418

33. Rodrigues CMP, Sola S, Sharpe JC, Moura JJG and Steer CJ (2003) Tauroursodeoxycholic acid prevents Bax-induced membrane perturbation and cytochrome $c$ release in isolated mitochondria. Biochemistry 42: 3070-3080

34. Hsu YT and Youle RJ (1998) Bax in murine thymus is a soluble monomeric protein that displays differential detergent-induced conformations. J. Biol. Chem. 273: 10777-10783

35. Garbo GM, Vicente MGH, Fingar V and Kessel D (2003) Effects of ursodeoxycholic acid on photodynamic therapy in a murine tumor model. Photochem. Photobiol. 78: 407-410

36. Morgan AR, Garbo GM, Keck RW and Selman SH (1988) New photosensitizers for photodynamic therapy: combined effect of metallopurpurin derivatives and light on transplantable bladder tumors. Cancer Res. 48: 194-198

37. Roberts WG, Shiau FY, Nelson JS, Smith KM and Berns MW (1988) In vitro characterization of monoaspartyl chlorin e6 and diaspartyl chlorin e6 for photodynamic therapy. J. Natl. Cancer Inst. 80: 330-336

38. Matern S, Marschall HU, Schill A, Schumacher B, Lehnert W, Sjovall J and Matern H (1991) Synthesis of ${ }^{13} \mathrm{C}$-labeled chenodeoxycholic, hyodeoxycholic, and ursodeoxycholic acids for the study of bile acid metabolism in liver disease. Clin. Chim. Acta 203: 77-89

39. Tserng KY and Klein PD (1977) An improved synthesis of $24-{ }^{13} \mathrm{C}$-labeled bile acids using formyl esters and a modified lead tetraacetate procedure. J. Lipid Res. 18: 400-403

40. Kochi J (1965) Formation of alkyl halides from acids by decarboxylation with lead (IV) acetate and halide salts. J. Org. Chem. 30: 3265-3271

41. Lee ST, Hoeflich KP, Wasfy GW, Woodgett JR, Leber B, Andrews DW, Hedley DW and Penn LZ (1999) Bcl-2 targeted to the endoplasmic reticulum can inhibit apoptosis induced by Myc but not etoposide in Rat-1 fibroblasts. Oncogene 18: 3520-3528

42. Schendel SL and Reed JC (2000) Measuring pore formation by Bcl-2 family proteins. Methods Enzymol. 322: 274-282 